\title{
The Impact of Gender, Parents' Education Level, and Socio-Economic Status on Turkish Students' Mathematics Performance
}

\author{
Rusli \\ Ministry of Marine and Fisheries, SUPM Sorong, West Papua, Indonesia \\ Rusliazis.ra@gmail.com
}

\begin{abstract}
This paper describes secondary data analyses that investigate the impact of gender, parents' education level, and socio-economic status upon Turkish students' mathematics achievement in the Program for International Student Assessment (PISA) 2009. The analyses were done quantitatively using t-tests, one-way ANOVA, correlation and linear regression. The findings revealed that gender differences and Turkish students' mathematics performance are statistically significant but practically not significant. Parents' education level had an impact on Turkish students' mathematics achievements. The index of Economic, Social and Cultural Status (ESCS) had a positive effect on mathematics achievements and ESCS was a significant predictor of Turkish students' mathematics performance. The findings seem to suggest that at the school level, the school environment is expected to build students' motivation in learning, and the teachers in the classroom setting are expected to provide extra hours and learning consultation services for students who need it. At the student level, students were expected to have high motivation in learning and are suggested to not rely on learning facilities provided by their parents. However, further research is required prior to making any recommendations on school policy, teaching, and learning practice in the classroom setting.
\end{abstract}

Keywords: students' mathematics performance, gender, parents' education level, socio-economic status

\section{Introduction}

Success in students' learning is affected by several factors including gender, parents' level education, and socio-economic status. Gender differences, socio-economic status, and mathematics achievement were studied in 2008 based on student performance on the mathematics subsection of a nationwide high school entrance examination in Turkey and revealed that there was a statistically significant difference in mathematics performance in favor of big cities based on their economic development level although the effect size was quite small indicating that practically the difference was not significant. In addition, the study also concluded that the socio-economic development level of the areas was not an essential factor for gender differences in mathematics performance (Isiksal \& Cakiroghi, 2008).

In relation to parents' education level and mathematics achievement, the role of the students' parents is paramount for students' future particularly in providing their children with science and knowledge including mathematics. Good parental awareness and good guidance in mathematics were hoped to create and develop children to have good learning outcomes in mathematics so that they were ready for facing the variety of science problems in the future. Dalyono (2010) claimed that parental awareness and parental guidance are influenced by parents' educational level. He asserts that parents' education level of students plays an important role in educating children especially in development of language. Additionally, he argues that parents with an elementary level of education tend to direct their 
children to basic knowledge and basic skills. Parents with a secondary level of education tend to able to direct their children to broader knowledge and skills, not only basic skills and knowledge itself. Parents with a college level of education tend to direct their children to be able to follow recent developments of science and technology.

Based on the brief explanations above it was thought that it would be interesting to explore the impact of gender differences, parents' education level, and socio-economic status on students' mathematics performance. This paper focuses on examining these three main issues. The purpose of this study was to explore the influences on Turkish students' mathematics outcomes.

\section{Research Questions and Hypothesis}

There are three research questions explored in this study as follows:

1. Is there a difference in mathematics achievements through gender?

2. Is there a difference in mathematics achievements through parents' education level?

3. What is the influence of index of Economic, Social, and Cultural Status (ESCS) on mathematics achievements?

The hypotheses of this study are as follows.

1. The null hypothesis $\left(\mathrm{H}_{0}\right)$ and alternative hypothesis $\left(\mathrm{H}_{\mathrm{a}}\right)$ of the research question number one are as follows.

$\mathrm{H}_{0}$ : There are no significant differences between mathematics achievements by gender.

$\mathrm{H}_{\mathrm{a}}$ : There is a significant difference between mathematics achievement by gender.

2. The null hypothesis $\left(\mathrm{H}_{0}\right)$ and alternative hypothesis $\left(\mathrm{H}_{\mathrm{a}}\right)$ of the research question number two are as follows.

$\mathrm{H}_{0}$ : There are no differences in mathematics achievements based on parents' education level.

$\mathrm{H}_{\mathrm{a}}$ : There are differences in mathematics achievement between at least one pair of groups.

3. The null hypothesis $\left(\mathrm{H}_{0}\right)$ and alternative hypothesis $\left(\mathrm{H}_{\mathrm{a}}\right)$ of the research question number three are as follows.

$\mathrm{H}_{0}$ : There are no influences of index of Economic, Social, and Cultural Status (ESCS) on mathematics achievements.

$\mathrm{H}_{\mathrm{a}}$ : There is influence of index of Economic, Social, and Cultural Status (ESCS) on mathematics achievements. 


\section{Methodology}

\section{Data Source and Participants}

The data source for this paper was gained from the 2009 administration of PISA, which is a standardized assessment program developed internationally by cooperating Organization for Economic Co-operation and Development (OECD) countries and conducted with 15-year old students in schools from participating countries (OECD, 2010). Target population of this study was 15-year old Turkish students who engaged in PISA 2009. The data included 4996 Turkish students consisting of 2551 male and 2445 female. A brief summary of gender from the sample of this study is presented in Table 1.

Table 1 .

A Summary of Turkish Students Participated in PISA 2009

\begin{tabular}{lll}
\hline Variable & Per cent & Valid per cent \\
\hline Gender & & \\
$\quad$ Female & 48.9 & 48.9 \\
$\quad$ Male & 51.1 & 51.1 \\
Total & & \\
$\quad$ Percentage & 100 & 100 \\
$\quad$ Total & 4996 & 4996 \\
\hline
\end{tabular}

\section{One-way ANOVA}

The descriptive statistics related to mathematics achievements across the seven groups indicating the highest educational level of parents are presented in Table 2. It can be seen clearly that students with the highest educational level of none were associated with the numerically smallest mean of the mathematics achievements $(M=388.64$ and $S D=79.22)$ and students with the highest educational level of parents educational level ISCED 5A, 6 were associated with numerically the highest mean of mathematics achievements $(M=517.62$ and $S D=92.28)$. There were $6(.1 \%)$ respondents who answered N/A and $93(1.9 \%)$ with missing data. The percentage of missing data was less than $5 \%$ so it was acceptable to use as it would not impact on the estimation of the whole population (Dong \& Peng, 2013). In order to examine the hypothesis on the differences between mathematics achievements by parents' education level, an ANOVA was undertaken. Prior to performing the ANOVA, the assumption of normality was tested and was concluded that it was met as the distributions of seven groups associated with skewness and kurtosis of less than $|2.0|$ and $|2.0|$ respectively (Schmider et al., 2010). 
Table 2.

Descriptive Statistics for Parents' Education Level across Mathematics Achievements

\begin{tabular}{lrllll}
\hline $\begin{array}{l}\text { Parents' } \\
\text { Education Level }\end{array}$ & \multicolumn{1}{l}{$N$} & $M$ & $S D$ & Skewness & Kurtosis \\
\hline None & 145 & 388.64 & 79.22 & .22 & .58 \\
ISCED 1 & 1568 & 424.28 & 81.43 & .32 & .18 \\
ISCED 2 & 1209 & 423.88 & 81.07 & .40 & .77 \\
ISCED 3B,C & 92 & 417.15 & 83.49 & .30 & .55 \\
ISCED 3A,4 & 971 & 471.63 & 85.79 & .22 & -.70 \\
ISCED 5B & 198 & 479.64 & 93.40 & -.14 & -.39 \\
ISCED 5A,6 & 714 & 517.62 & 92.28 & & -.43 \\
\hline
\end{tabular}

*Notes: N/A: 6 (.1\%); Missing: 93 (1.9\%)

In order to investigate possible differences in mathematics achievement between students based on their highest parents' educational level (HISCED), a one-way ANOVA was conducted. The study found evidence that there was a difference in mathematics achievements based on HISCED status ( $\mathrm{F}=149.51(6,4890), \mathrm{p}<.0001)$. Thus, the null hypothesis of no differences in mathematics achievements based on parents' education was rejected. The $\omega^{2}=.154$ indicated that roughly $15 \%$ of the variation in the mean of mathematics achievements was attributable to differences between the seven groups of parents' education level.

Table 3

Results of ANOVA

\begin{tabular}{lcllll}
\hline & Sum of Squares & df & Mean Square & F & Sig. \\
\hline Between Groups & 6383981.41 & 6 & 1063996.90 & 149.513 & .000 \\
\hline Within Groups & 34799356.5 & 4890 & 7116.43 & & \\
\hline Total & 41183337.9 & 4896 & & & \\
\hline
\end{tabular}

To evaluate the nature of discrepancies between the seven groups means further, the statistically significant ANOVA was followed-up with the Tukey's post-hoc tests (Field, 2009). These results are presented in Table 4 and indicate that students' with parents' highest educational level of ISCED 5A $(M=128.98)$ scored significantly higher that the group 1(none), group 2 (ISCED 1), group 3 (ISCED2), group 4 (ISCED3B, C), group 5 (ISCED 3A, 4), and group 6 (ISCED 5B). The effect size of these significant pairs differences was estimated at $1.53,1.10,1.11,1.19, .54$, and .45 respectively. The mean differences of students with parents' in the highest educational level of none $(M=388.64)$ and students with parents' educational level of ISCED 3B, C $(M=417.15)$ statistically were not significant. The effect size of this pairwise was approximately at .34 . 
Table 4.

Turkey Post Hoc Results and Effect Size of Mathematics Achievements by the Highest Parents' Educational Level

\begin{tabular}{lllllllll}
\hline \multicolumn{7}{c}{ Mean Differences $\left(\bar{X}_{l}-\bar{X}_{J}\right)$} \\
(Effect Size is indicated in parentheses) \\
\hline Group & Mean & 1. & 2. & 3. & 4. & 5. & 6. & 7. \\
\hline 1. None & 388.64 & 0.00 & & & & & & \\
2. ISCED 1 & 424.28 & $35.64^{*}$ & 0.00 & & & & & \\
3. ISCED 2 & 423.88 & $35.24^{*}$ & 0.40 & 0.00 & & & & \\
4. ISCED 3B, C & 417.15 & 28.51 & 7.13 & 6.73 & 0.00 & & & \\
5. ISCED 3A, 4 & 471.63 & $82.98^{*}$ & $47.34^{*}$ & $47.74^{*}$ & $54.47^{*}$ & 0.00 & & \\
6. ISCED 5B & 479.64 & $91.00^{*}$ & $55.35^{*}$ & $55.76^{*}$ & $62.49^{*}$ & 8.01 & 0.00 & \\
7. ISCED 5A, 6 & 517.62 & $128.98^{*}$ & $93.33^{*}$ & $93.74^{*}$ & $100.47^{*}$ & $45.99^{*}$ & $37.98^{*}$ & 0.00 \\
& & $(1.53)$ & $(1.10)$ & $(1.11)$ & $(1.19)$ & $(0.54)$ & $(0.45)$ & \\
\hline
\end{tabular}

*.The mean difference is significant at the .05 level.

\section{Correlation}

To examine the relationship between the index of ESCS and mathematics achievements, Pearson's correlation was computed. The results indicated that there was a positive and significant correlation between ESCS and mathematics achievements, $r=.45$, $n=4967, p<.001$. It suggests that there was a medium relationship between ESCS and mathematics achievements (Cohen, 1992; Field, 2009). R-squared was .20, which implies that $20 \%$ of variance of mathematics achievements is associated with the variance of ESCS. In this case, missing data is $29(.58 \%)$, which is very small and less than $5 \%$. This missing data would not affect the estimation of the whole population.

\section{Linear Regression}

To investigate the hypothesis of the research question number three, a simple linear regression was conducted to assess if ESCS predicted mathematics achievements. Prior to analysis, the assumption of normality of independent variable (ESCS) was examined and it was concluded that it was met as its distribution was associated with skewness and kurtosis less than $|2.0|$ and $|2.0|$ respectively (Schmider et al., 2010).

Table 5 .

Descriptive Statistics ESCS and Mathematics Achievements

\begin{tabular}{lllll}
\hline & $M$ & $S D$ & Skewness & Kurtosis \\
\hline ESCS & -1.16 & 1.20 & .32 & -.51 \\
Mathematics achievements & 446.91 & 91.98 & .34 & -.11 \\
\hline
\end{tabular}

The assumption of linearity was met by generating scatter plots of the outcome variable against the explanatory variable (see Figure 1). 


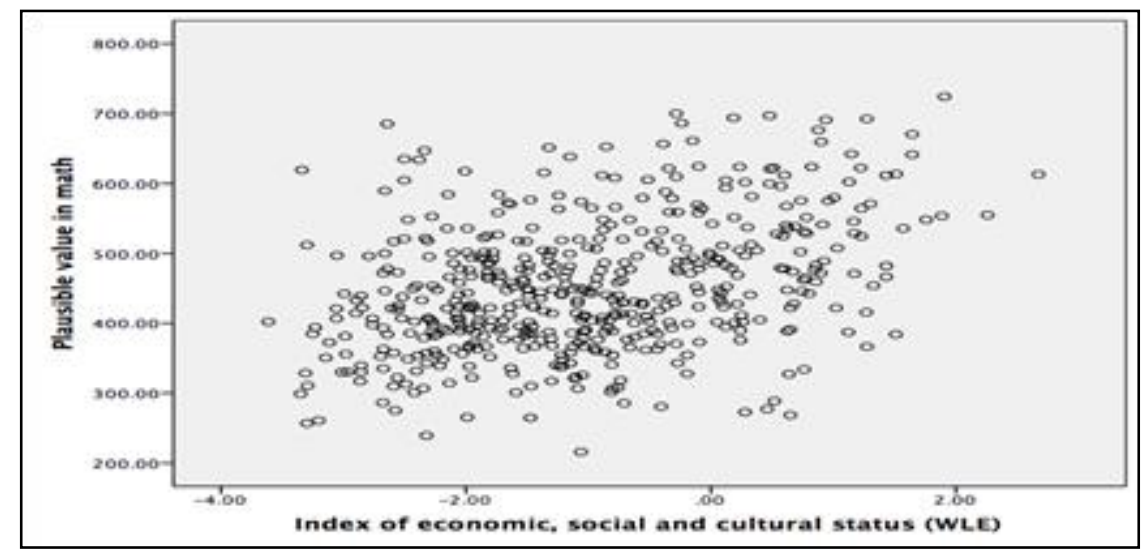

Figure 1. Scatter plots of ESCS against plausible value in mathematics

The results of linear regression were significant, $F(1,4965)=1281.46, p<.001, R^{2}=$ .20 , suggesting that approximately $20 \%$ of the variation in the mathematics achievement score was predicted by the ESCS score. ESCS was a significant predictor of mathematics achievements, $B=34.56, p<.001$ suggesting that for every one unit increase in ESCS then mathematics achievements increased by 34.56 units. Therefore, we rejected the null hypothesis. Results of linear regression are presented in Table 6 below.

Table 6.

Results of Linier Regression with ESCS Predicting Mathematics Achievements

\begin{tabular}{|c|c|c|c|c|c|}
\hline & $B$ & $S E$ & $\beta$ & $t$ & $p$ \\
\hline Constant & 487.63 & 1.62 & & 301.64 & .00 \\
\hline ESCS & 34.56 & .97 & .45 & 35.80 & .00 \\
\hline
\end{tabular}

\section{Discussion}

In this study, analysis of data showed that gender differences and mathematics achievement was statistically significant. Findings also revealed that male students were associated with a statistically significant larger mean of mathematics achievement than female students. Although, the mean difference of mathematics achievement between male and female was statistically significant, the effect size was quite small suggesting that the mean difference of mathematics achievement by gender was not practically significant. The findings of this research are similar to the previous study conducted by Isiksal and Cakiroghi in Turkey in 2008. They found that gender differences regarding to mathematics achievements of Turkish middle school students based on level of the economic development city was statistically significant but it was not significant practically.

In relation to the mathematics achievements against the parents' educational level, statistical findings in this study revealed that there was a significant difference in mathematics achievements according to the parents' education level. Students with parents having an educational level ISCED 5A, 6 showed a significant mean difference compare to other groups. The effect size between ISCED 5A, 6 and four groups, which are NONE, ISCED 1, 
ISCED 2, and ISCED 3B, C was quite large indicating that it was also practically significant and the effect size between ISCED 5A, 6 and ISCED 3A, 4 and ISCED 5B was quite small suggesting that practically it was not significant (Cohen, 1992).

Regarding to the influence of index of ESCS on mathematics achievements, correlation analysis revealed that there was positive and significant relationship between these two variables. ESCS has a medium relationship with mathematics achievement. Linear regression showed an increase in one unit in ESCS would increase mathematics achievements by roughly 34.56 . It means that there were positive linear relationships between ESCS and mathematics achievement. Additionally, the results of the linear regression also indicated that ESCS score predicted approximately $20 \%$ variation of mathematics achievement. Therefore, it could be concluded that ESCS was a significant predictor of mathematics achievement. Indeed, the ESCS score had a positive influence on mathematics achievement. Based on correlation and linear regression analysis, it could be said generally that if the index scores of ESCS of students in Turkey were good then students' performance in mathematics would increase.

In conclusion, there are three main issues of the findings in this study. First of all, the findings of this study have revealed that gender differences and mathematics achievement in Turkish students who participated in PISA 2009 are statistically but not practically significant. Secondly, parents' education level of Turkish students in this research has an impact on Turkish students' mathematics achievements. The last main point of the result in this study is the index of ESCS has a positive impact on mathematics achievement. ESCS and mathematics achievement show a positive and linear relationship. ESCS is a significant predictor of mathematics achievements.

\section{References}

Cohen, J. (1992). A power primer. Psychological Bulletin, 112(1), 155-159. https://doi.org/10.1037/0033-2909.112.1.155

Dalyono, M. (2010). Educational psychology. Jakarta: Rineka Cipta.

Dong, Y., \& Peng, C.-Y. J. (2013). Principled missing data methods for researchers.

SpringerPlus, 2(1), 1-17.

Field, A. P. (2009). Discovering statistics using SPSS. London: Sage.

siksal, M., \& Cakiroghi, E. (2008). Gender differences regarding mathematics achievement: The case of Turkish middle school students. School Science and Mathematics, 108(3), 113-120.

Organization for Economic Co-operation and Development (OECD). (2010). PISA 2009 at a glance. OECD Publishing. https:// doi.org/10.1787/9789264095298-en 
Schmider, E., Ziegler, M., Danay, E., Beyer, L., \& Bühner, M. (2010). Is it really robust? Reinvestigating the robustness of ANOVA against violations of the normal distributions assumptions. Methodology: European Journal of Research Methods, 6(4), 147-151.

Sullivan, G. M., \& Feinn, R. (2012). Using Effect size — or why the p value is not enough. Journal of Graduate Medical Education, 4(3), 279-282. 